\title{
La cooperativa en el ordenamiento jurídico cubano. Una aproximación crítica a la luz del actual proceso de perfeccionamiento del modelo económico en el país
}

\author{
Orestes Rodríguez Musa y Orisel Hernández Aguilar² \\ Universidad de Pinar del Río
}

Recibido: $\quad 20.06 .11$

Aceptado: 12.07 .11

Sumario: I. Una introducción necesaria. II. Marco jurídico de la cooperativa en Cuba. Limitaciones y propuestas para su perfeccionamiento: 2.1. Naturaleza jurídica. 2.2. Reconocimiento del derecho de asociarse en cooperativas. 2.3. Sector de la economía en que se desarrolla. 2.4. Fines a cuyos efectos se concibe legalmente. 2.5. Funcionamiento. III. A modo de conclusión.

Resumen: El objetivo de este trabajo es aportar algunas valoraciones en torno a la plataforma normativa que en la actualidad regula a la cooperativa en Cuba, a fin de contribuir a su perfeccionamiento, pues forma parte de la reestructuración del modelo económico previsto en los Lineamientos de la Política Económica y Social del Partido y la Revolución (incluidas en los puntos del 25 al 29, bajo el título "LAS COOPERATIVAS», como parte del nuevo "MODELO DE GESTIÓN ECONÓMICA») aprobados por el VI Congreso del Partido Comunista de Cuba y que regirán durante los próximos años las transformaciones emprendidas por el país.

Palabras clave: cooperativa, lineamientos y marco jurídico.

Abstract: The aim of this study is to provide some criteria about the current platform that rules the context of the cooperative in Cuba, in order to contribute to their improvement as part of the restructuring of the economic model under the Guidelines of the Economic and Social Policy of the Party and the Revolution (that includes it in its points 25 to 29, under the title of «Cooperatives» as part of the new «Model of Economic Manage-

1 Máster en Derecho Constitucional y Administrativo, Profesor de Derecho Constitucional, Departamento de Derecho, Facultad de Ciencias Sociales y Humanísticas, Universidad de Pinar del Río, Cuba. Investigador de la Asociación Internacional de Derecho Cooperativo (AIDC).E-mail: musa@fcsh.upr.edu.cu

2 Máster en Derecho Constitucional y Administrativo, Profesora de Teoría General del Derecho y Derecho Romano, Departamento de Derecho, Facultad de Ciencias Sociales y Humanísticas, Universidad de Pinar del Río, Cuba. E-mail: oriselha@fcsh.upr.edu.cu 
ment») approved by the Sixth Congress of the Communist Party of Cuba and that will rule for the next few years the changes undertaken by the country.

Key words: cooperative, guidelines and legal framework. 


\section{Una introducción necesaria}

En Cuba se impone hoy una reestructuración del modelo económico: los hechos demuestran la necesidad de aligerar la maquinaria administrativa, desconcentrar y descentralizar, aumentar la autonomía local y, en sentido general, terminar con las manifestaciones de sobreprotección o paternalismo estatal en la satisfacción de las necesidades sociales. Por ello, se ha planteado desde la dirección del Estado que «...estamos en el deber de (...) transformar concepciones y métodos que fueron los apropiados en su momento, pero han sido ya superados por la propia vida» ${ }^{3}$.

En este mismo sentido, la Central de Trabajadores de Cuba ha declarado que el país enfrenta la urgencia de avanzar económicamente, organizar mejor la producción, potenciar las reservas de productividad y elevarla, mejorar la disciplina y la eficiencia para así satisfacer nuestras necesidades. Por tanto - y como parte del proceso de actualización del modelo económico- las proyecciones de la economía para el periodo 2011-2015, prevén en el plan del presente año, la reducción de más de 500000 trabajadores en el sector estatal, donde el exceso de plazas sobrepasa el millón, ${ }^{4}$ a los que habrá de asegurárseles la posibilidad de obtención —-por medios legales— de los recursos necesarios para su existencia y la de su familia, así como de su desarrollo espiritual y cultural.

Como alternativa de empleo de los trabajadores que en una entidad o puesto de trabajo resulten disponibles, se ampliará y se diversificará el actual horizonte de opciones, con nuevas formas de relaciones laborales no estatales, entre las que se hayan previstas las cooperativas. ${ }^{5}$

3 Discurso pronunciado por el entonces Primer Vicepresidente de los Consejos de Estado y de Ministros, General de Ejército Raúl Castro Ruz, en el acto central con motivo del aniversario 54 del asalto a los cuarteles Moncada y Carlos Manuel de Céspedes, en la Plaza de la Revolución Mayor General Ignacio Agramonte Loynaz de la ciudad de Camagüey, el 26 de julio del 2007, en www.cubadebate.cu, consultado en octubre de 2009. Más recientemente ha dicho también en este sentido Marino Murillo Jorge, Vicepresidente del Consejo de Ministros y Ministro de Economía y Planificación, en su intervención por la clausura del X Congreso de la ANAP, efectuado en la Sala Universal de las FAR, el 16 de mayo de 2010 (en www.cubadebate.cu/especiales/2010/05/17/ actualizar-nuestro-modelo-economico, consultado en octubre de 2010) que: «Estas circunstancias demandan una actualización de nuestro modelo económico, que preserve los principios de justicia del socialismo.»

4 Pronunciamiento de la Central de Trabajadores de Cuba del 13 de septiembre 2010, en www.cubadebate.cu/noticias/2010/09/13/reducira-cuba-medio-millon-deplazas-en-el-sector-estatal, consultado en octubre de 2010.

5 Idem. 
En los Lineamientos de la Política Económica y Social del Partido y la Revolución aprobados el pasado abril por el VI Congreso del Partido Comunista de Cuba (en lo adelante Lineamientos) ${ }^{6}$, que regirán durante los próximos años las transformaciones emprendidas por el país para perfeccionar su modelo socioeconómico, resaltan -a los efectos de nuestro estudio- los puntos del 25 al 29, pues se hallan bajo el título de "LAS COOPERATIVAS», señalándose que estas entidades formarán parte de un nuevo "MODELO DE GESTIÓN ECONÓMICA» que reconocerá y estimulará otras formas empresariales —además de la preponderante empresa estatal - para la producción de bienes o la prestación de servicios en disímiles esferas de la economía, a fin de elevar la productividad del trabajo.

Sin embargo, debemos plantearnos una lógica interrogante: ¿En qué medida las bases y principios que brinda hoy el ordenamiento jurídico, son suficientes para la instrumentación de la cooperativa como una alternativa empresarial efectiva en el país? El objetivo de este trabajo es, por tanto, aportar algunas valoraciones en torno a la plataforma normativa que encuentra la cooperativa en el actual contexto cubano, a fin de contribuir a su necesario perfeccionamiento.

\section{Marco jurídico de la cooperativa en Cuba. Limitaciones y propuestas para su perfeccionamiento}

El vigente marco jurídico de la cooperativa en Cuba es resultado de un contexto diferente al que vive el país, en tanto respondió al proceso de radicalización de la revolución popular cubana de 1959 en su enfrentamiento con lo más reaccionario de la burguesía nacional y con el Gobierno norteamericano, que la condujeron a encontrar sustento e inspiración en el modelo socialista soviético, superado ya por la historia en muchos de los postulados que entonces se enarbolaban como el inequívoco camino a seguir para la construcción de un sistema socioeconómico más justo que el capitalismo. No obstante, es necesario reconocer que algunas adaptaciones en esta normativa fueron introducidas a partir del año 1992 tras la caída del campo socialista y la inmersión de Cuba en el mercado económico mundial.

6 Vid. Lineamientos de la Política Económica y Social del Partido y la Revolución, aprobado por el VI Congreso del Partido Comunista de Cuba el 18 de abril de 2011, en www.cubadebate.cuwp-contentuploads201105folleto-lineamientos-vi-cong.pdf, consultados en junio de 2011. 
En materia de cooperativas, las regulaciones con que el ordenamiento jurídico cubano cuenta hoy son, básicamente: con carácter general el artículo 20 de la Constitución de la República de 1976 (actualizada); con carácter supletorio los artículos del 145 al 149 del Código Civil, Ley 59, de 16 de julio de 1987 (en lo adelante CC), y con carácter especial la Ley de Cooperativas de Producción Agropecuaria y de Créditos y Servicios, Ley 95, del 2 de noviembre de 2002 (en lo adelante LCPACS), y el Decreto Ley 142, de 20 de septiembre de 1993, sobre las Unidades Básicas de Producción Cooperativa.

Sobre esta base, pasemos a continuación a valorar algunas de las limitaciones más significativas que tal legislación establece al desarrollo cooperativo del país en el presente contexto de actualización del modelo económico cubano, a la vez que razonamos algunas propuestas para su perfeccionamiento.

\subsection{Naturaleza jurídica}

Nos parece oportuno para nuestro análisis partir de este tópico, ya que una correcta delimitación de la naturaleza jurídica de una institución nos permite no solo determinar el régimen jurídico aplicable a ella (registro, competencia judicial, normas principales y supletorias a aplicar, etc.), sino además el papel que le corresponde jugar al interior del orden socioeconómico y político en que se deba desarrollar.

Con respecto a la cooperativa el asunto se torna complicado, pues la naturaleza jurídica de una institución, se hace depender —en última instancia- del carácter público o privado que la misma posea, cuestión que en este caso no es clara.

Al respecto, el peruano TORRES Y TORRES LARA advierte que para la mayoría de los autores, no hay dudas de que la cooperativa es una persona jurídica de Derecho Privado, ya que su origen está en la voluntad de un grupo de individuos y no en el ius imperium, o sea que se rige por la voluntad de los socios sin interferencias del Estado, quienes además definen la oportunidad de su disolución y liquidación. ${ }^{7}$ Sin embargo, más adelante el propio autor señala que "...tenemos que admitir que la cooperativa no se comporta exactamente como la mayor parte de los entes del Derecho Privado. De ahí que al-

7 Vid. Torres y Torres Lara, C.: Naturaleza jurídica de la cooperativa, Lima, 1983, en http://www.teleley.com/librosdederecho/7tc.pdf, consultado en septiembre de 2010, p. 114. 
gunos autores clasifican a la cooperativa como una persona jurídica de Derecho Social. Es decir en posición intermedia o singular entre las personas jurídicas de Derecho Privado y las del Público....» ${ }^{8}$.

Estos criterios demuestran una teoría - por joven - inacabada o en construcción que intenta despegarse — pues lo merece- de las viejas doctrinas liberales que hasta hoy han intentado separar de forma dogmática lo público de lo privado, olvidando la dialéctica relación entre los componentes sociales. Por tanto, la cooperativa exige de un asidero jurídico que rompa con los viejos cánones y la guíe en sus revolucionarios objetivos, salvando su autonomía e identidad pero sin que ello suponga olvidar sus responsabilidades sociales.

Con base en esta dicotomía, han surgido varias tesis que intentan explicar la naturaleza jurídica de la cooperativa, y que GADEA, SACRITÁN Y VARGAS VASSEROT han agrupado en tres posiciones básicas: la que la considera una asociación; la que la considera una sociedad y la que la considera una categoría autónoma. ${ }^{9}$ En otras ocasiones, sobre la base de las ideas anteriores, hemos tomado partido por la tercera de ellas. ${ }^{10}$

Análisis aparte merece - por lo que representa en la historia jurídica cubana - la manera en que asumió y formuló la legislación soviética a la naturaleza jurídica de la cooperativa. En este sentido, debemos recordar ante todo que el Derecho que guió los pasos del socialismo real, fue resultado de una fuerte lucha de clase contra la propiedad privada sobre los medios de producción, en pos de la apropiación de éstos por obreros y campesinos; donde la fórmula legal para conseguirlos fue la proclamación del predominio casi absoluto — dependiendo del contexto histórico y geográfico del que se tratare- de la propiedad social socialista, expresada en la propiedad estatal y en la propiedad cooperativa sobre el patrimonio destinado a producir riquezas materiales y espirituales.

Este proceso de confrontación política tuvo alta incidencia para el campo de las Ciencias Jurídicas de otrora, en las que se confundieron categorías de la Economía y el Derecho para dar paso a la concepción que define a la cooperativa como una forma de propiedad, que fue

8 Idem., p. 115.

9 Vid. Gadea, E.; Sacristán, F. y Vargas Vasserot, C.: Régimen jurídico de la sociedad cooperativa del siglo XXI. Realidad actual y propuestas de reforma, Dykiston SL, Madrid, 2009, pp. 70-83.

10 Vid. Rodríguez Musa, O.: "La cooperativa como figura jurídica. Antecedentes, realidad y perspectivas constitucionales en Cuba», en Boletín de la Asociación Internacional de Derecho Cooperativo n. ${ }^{\circ} 44$, Bilbao, 2010, pp. 46-49. 
asumida en el ordenamiento jurídico cubano a partir del 24 de febrero de 1976 con la proclamación del texto constitucional socialista.

El artículo 20 de este cuerpo jurídico (reformado en 1992), resalta desde un inicio a la cooperativa como una forma de propiedad: "Esta propiedad cooperativa es reconocida por el Estado...». Por su parte, el CC, al ubicar a la cooperativa en sU TÍTULO II: DERECHO DE PROPIEDAD, CAPÍTULO II: FORMAS DE PROPIEDAD, bajo la denominación de la SECCIÓN TERCERA: Propiedad cooperativa, es muy clara la concepción que asume para entender la esencia de la figura.

Si bien la cooperativa es - también - una forma de propiedad (colectiva), a nuestra consideración esta manera de entenderla resulta reduccionista, pues pondera las facultades de poseer, usar, disfrutar y disponer de los bienes de su propiedad ${ }^{11}$ en detrimento de sus intrínsecos principios de funcionamiento a lo interno y a lo externo.

La cooperativa, para conseguir la socialización de la propiedad a que está llamada en Cuba, debe configurarse por el Derecho como un espacio asociativo, que propicie el desarrollo efectivo de un proceso de producción-apropiación de bienes y servicios en el que prime la equidad, la voluntariedad y la autonomía en su constitución y funcionamiento, al interior de un clima institucional que guíe su contribución a la solución de los problemas económicos y culturales de la comunidad en que se desarrolla.

\subsection{Reconocimiento del derecho de asociarse en cooperativas}

Si bien el artículo 54 de la Constitución de la República reconoce con carácter general el derecho de asociación, el desarrollo legal-ordinario de este derecho en la Ley de Asociaciones, Ley n. ${ }^{\circ}$ 54, de 27 de diciembre de 1985, solo contempla las formas asociativas de carácter científico o técnico, cultural, artístico, deportivas, de amistad y solidaridad, y otras; con la expresa exclusión de las organizaciones de masas y sociales a que se refiere el artículo 7 de la Constitución, las asociaciones eclesiásticas o religiosas, las cooperativas de producción agropecuaria, las de crédito y servicio, y otras autorizadas por la ley, ${ }^{12}$ salvedad que parece obedecer a la aplicación del principio de especialidad en el tratamiento legislativo de las últimas formas asociativas.

11 Vid. artículos 20 de la Constitución socialista cubana (actualizada) y 146 del CC.

12 Vid. artículo 2 de la Ley de Asociaciones, Ley n. ${ }^{\circ}$ 54, de 27 de diciembre de 1985. 
No obstante, y aunque se reconoce en el artículo 20 del magno texto cubano que las cooperativas que se desenvuelven en el sector agropecuario (las únicas existentes, ya sean de producción o de créditos y servicios) son consecuencia del «derecho a asociarse», la expresa alusión en el precepto de los sujetos destinatarios para esta manifestación concreta de dicho derecho («Los agricultores pequeños tienen derecho a asociarse entre sí...»), pudiera interpretarse como un límite constitucional al derecho de asociarse en cooperativas, lo que merecería una explicación histórica:

El Estado cubano, desde la proclamación de su carácter socialista, ha buscado mecanismos de socialización de la propiedad, como vía para excluir «...la división de los hombres en poseedores de los medios de producción y desposeídos de ellos, y que las relaciones personales se basen en la colaboración y ayuda mutua» ${ }^{13}$. Este propósito marxista y genuinamente revolucionario, desembocó muchas veces en la copia mimética y acrítica del modelo de dirección de la economía soviética, ante la ausencia - o ensombrecimiento tal vez- de otros referentes. Por ello, en marzo de 1968, prácticamente todos los medios útiles para la producción que no habían sido intervenidos, pasaron a propiedad estatal, y así se entendió terminado el proceso de socialización de la propiedad privada ${ }^{14}$.

Sobre esta base, la Constitución socialista cubana, tras su promulgación el 24 de febrero de 1976, estableció en su artículo 14 que: «En la República de Cuba rige el sistema socialista de economía basado en la propiedad socialista de todo el pueblo sobre los medios de producción y en la supresión de la explotación del hombre por el hombre».

El complemento y principal modo de expresión de este principio constitucional, que rectorea desde entonces el modelo económico cubano ${ }^{15}$, ha de hallarse en el precepto que consigna: «La propiedad estatal socialista, que es la propiedad de todo el pueblo...», para, taxativamente y en reglón seguido, definir el objeto de esta forma de propiedad con una amplísima gama de objetivos económicos de la que escapan, por excepción expresa, "....las tierras que no pertenecen a los agricultores pequeños o a cooperativas integradas por los mismos...».

13 Álvarez Tabío, F.: Comentarios a la Constitución socialista cubana, Ed. Pueblo y Educación, La Habana, 1989, p. 84.

14 Vid. Casullera Arrate, R.: «La propiedad personal en nuestra Constitución», en Revista Jurídica n. ${ }^{\circ}$ 10, La Habana, enero-marzo de 1986, pp. 50-60.

15 No obstante, con la reforma constitucional de 1992 sufre una importante transformación al introducirse el adjetivo «fundamentales» para caracterizar a los medios de producción de propiedad social. 
De esta manera, poco espacio quedó para la conformación de cooperativas, que fueron constreñidas constitucionalmente por la propiedad estatal socialista. Se limitó su reconocimiento al artículo 20, que después de definir la propiedad de los agricultores pequeños, expresó el derecho de estos a asociarse entre sí, autorizándose la organización de cooperativas agropecuarias como otra forma de propiedad colectiva, junto a la estatal16. Por esta razón, cuando el Código Civil determina taxativamente los bienes que pueden ser objeto de propiedad de las cooperativas, lo hace -inequívocamente - aludiendo a los que pertenecen a los agricultores pequeños ${ }^{17}$ siendo aún más clara la legislación especial que, desde sus propios títulos, muestran con claridad a quienes van destinadas a garantizar el derecho de asociarse en cooperativas.

Sin embargo, la actualidad del país muestra hoy una coyuntura diferente que aconseja nuevas miradas hacia nuestro ordenamiento jurídico en materia de cooperativas: en consonancia con los cambios que viene realizando el país en su modelo económico, se han publicado recientemente en la Gaceta Oficial de la República de Cuba ${ }^{18}$, varias disposiciones jurídicas encaminadas a propiciar la ampliación de esta mo-

16 Texto (original) del artículo 20 de la Constitución socialista cubana de 1976: «El Estado reconoce la propiedad de los agricultores pequeños sobre sus tierras y otros medios e instrumentos de producción, conforme a lo que establece la ley.

Los agricultores pequeños tienen derecho a asociarse entre sí, en la forma y con los requisitos que establece la ley, tanto a los fines de la producción agropecuaria como a los de la obtención de créditos y servicios estatales.

Se autoriza la organización de cooperativas agropecuarias en los casos y en la forma que la ley establece. La propiedad cooperativa es una forma de propiedad colectiva de los campesinos integrados en ellas.

El Estado apoya la producción cooperativa de los pequeños agricultores, así como la producción individual, que contribuya al auge de la economía nacional.

El Estado promueve la incorporación de los agricultores pequeños, voluntaria y libremente aceptada por éstos, a los planes y unidades de producción agropecuaria.»

17 Artículo 148.1. del CC: "La propiedad de las cooperativas puede tener como objeto:

a) la tierra y otros medios e instrumentos de producción, las viviendas, instalaciones, medios culturales recreativos y otros bienes aportados por sus miembros y los construidos o adquiridos por las mismas.

b) sus animales y plantaciones, su producción agropecuaria y forestal y otras;

c) sus fondos y recursos financieros;

ch) los fondos creados con el aporte de sus integrantes; y

d) otros bienes.

2. La tierra y cualesquiera otros bienes que las cooperativas reciban en usufructo o arrendamiento no son propiedad de las mismas.»

18 Vid. Gaceta Oficial n. ${ }^{\circ} 011$ Ext. Especial de primero de octubre de 2010 y Gaceta Oficial n. ${ }^{\circ} 012$ Ext. Especial de 8 de octubre de 2010. 
dalidad de trabajo, respaldados —en alguna medida - por los medios e instrumentos de trabajo de propiedad personal (con reconocimiento constitucional ${ }^{19}$ ) que comienzan a adquirir una importancia sin precedentes.

En tal sentido, el Decreto-Ley n. ${ }^{\circ} 141$, del 8 de septiembre de 1993, «sobre el ejercicio del trabajo por cuenta propia», hasta entonces complementado por la Resolución n. ${ }^{\circ}$ 9, del 11 de marzo de 2005, del Ministro de Trabajo y Seguridad Social, «Reglamento del ejercicio del trabajo por cuenta propia», pasa a ser desarrollado por la Resolución n. ${ }^{\circ}$ 32, del 7 de octubre de 2010, emanada del propio Ministerio y contentiva de un nuevo reglamento - del mismo nombre- que define taxativamente 178 actividades (60 más que su predecesor ${ }^{20}$ ) que pueden ser realizadas al amparo de estas disposiciones jurídicas. ${ }^{21}$

Al analizar el nuevo contexto, debemos entender el importante potencial que significan estos trabajadores individuales, pequeños y dispersos, para la configuración de las emergentes cooperativas cubanas. Ellos pudieran constituir en la ciudad, el sujeto homólogo del pequeño agricultor en el campo, salvando las diferencias relativas a la propiedad de los bienes que decidan aportarse a la actividad cooperada. Las razones económicas, políticas y sociales que aconsejan y legitiman la instrumentación legal del derecho a asociarse en cooperativa a los segundos, debe valer - con igual fuerza - para los primeros.

\subsection{Sector de la economía en que se desarrolla}

Las cooperativas proporcionan servicios para satisfacer una o varias de las necesidades socioeconómicas experimentadas por núcleos más o menos numerosos de personas. Dichas necesidades no pueden ser satisfechas - o lo son de forma insuficiente- cuando estos individuos operan de manera aislada. Sin embargo, una vez que aúnan y complementan sus esfuerzos todas estas personas que se hallan en condicio-

19 Vid. artículo 21 de la Constitución socialista cubana de 1976 (actualizada).

20 Cfr. anexo 1 de ambos Reglamentos.

21 Véase también en este sentido y en materia de transporte, la Resolución n. ${ }^{\circ} 399$, del 7 de octubre de 2010, del Ministerio del Transporte, «Reglamento de la licencia de operación de transporte para personas naturales» (que deja sin efecto la Resolución n. ${ }^{\circ} 73$, del 22 de abril de 2005, «Reglamento de la Licencia de Operación del Transporte»), la cual establece el procedimiento para otorgar la Licencia de Operación de Transporte a personas naturales, para poder prestar servicios del transporte terrestre, marítimo y fluvial en el territorio nacional o en sus aguas jurisdiccionales, tanto de pasajeros como de cargas. 
nes semejantes, logran conseguir una solución satisfactoria a sus problemas.

Variadas son las necesidades a cuya satisfacción pueden estar destinadas las actividades socioeconómicas que realizan las cooperativas en prácticamente todos los sectores o ramas de la economía. En este sentido se distingue, atendiendo a la naturaleza de las funciones que desempeñan, tres tipos fundamentales: a) cooperativas de distribución [proporcionan a sus asociados los artículos y servicios que estos necesitan, en las mejores condiciones posibles de calidad y precio]; b) cooperativas de colocación de la producción [agrupan productores y procuran colocar los resultados de sus producciones en las mejores condiciones posibles de precio, regularidad y seguridad] y c) cooperativas de trabajo [agrupan a obreros, técnicos, profesionales, etc. que organizan en común su trabajo, a fin de proporcionarles fuentes de ocupación estables y convenientes].22

Sin embargo en Cuba - por las razones tratadas supra- el marco legal actual solo contempla la creación de cooperativas en el sector agropecuario de la economía, lo que ha generado su estudio y desarrollo jurídico únicamente desde el Derecho Agrario.

Para explicarlo, el profesor AzcuY — a partir del pensamiento del comandante Fidel Castro Ruz - razona que «...hubiera sido un retroceso desde el punto de vista social convertir a los obreros en propietarios cooperativos. La organización cooperativa quedó entonces como un escalón de avance para los campesinos que continuaban la explotación individual de la tierra» ${ }^{23}$. Del análisis de esta idea queda claro que esta figura, como fenómeno agropecuario, fue percibida como intermedia y transitoria entre la propiedad estatal y la privada o individual, para la transformación de la última en la primera, ya que hubiese carecido de fundamento político e histórico, imponer la conversión de la propiedad de los pequeños agricultores, en propiedad estatal socialista, cuando había sido un objetivo expreso y una conquista del proceso revolucionario, la entrega de la tierra a los que la trabajan ${ }^{24}$.

22 Vid. Kaplan de Drimer, A. y Drimer, B.: Las cooperativas. Fundamentos-HistoriaDoctrina, Ed. Intercoop, Buenos Aires, 1981, pp. 156 y ss.

${ }^{23}$ Azcuy, H.: "Análisis de la Constitución cubana», en Revista Papeles de la FIM n. ${ }^{\circ}$ 14, Madrid, 2000, p. 53.

24 «Nosotros llamamos pueblo (...) a los cien mil agricultores pequeños, que viven y mueren trabajando una tierra que no es suya, contemplándola siempre tristemente como Moisés a la tierra prometida, para morirse sin llegar a poseerla, que tienen que pagar por sus parcelas como siervos feudales una parte de sus productos, que no pueden amarla, ni mejorarla, ni embellecerla, plantear un cedro o un naranjo porque igno- 
No obstante, el carácter agropecuario o no de la cooperativa ha motivado interpretaciones doctrinales diversas al texto constitucional cubano socialista cubano, pese a que éste — desde sus proclamación en 1976 - las caracteriza como instituciones agropecuarias: Para algunos «la Constitución reconoce a la cooperativa como una propiedad agraria, sin hacerla extensiva a ningún otro tipo de explotación económica» 25 , viéndose así —en la definición constitucional de la cooperativa - un límite para la expansión legal de la figura a otros sectores de la economía; para otros, en cambio, «la enumeración constitucional de las formas de propiedad no es taxativa, por lo cual es factible que la ley establezca la autorización para otras modalidades o posibilidades de la propiedad cooperativa» 26 .

Por nuestra parte, consideramos que la empresa cooperativa resulta una forma ideal para que la ley desarrolle la esencia popular del texto constitucional más allá de los sectores económicos en que hoy lo hace: No olvidemos que se trata de entidades encaminadas a satisfacer - sobre la base del esfuerzo propio y la ayuda mutua - las necesidades sociales y económicas de sus miembros, para cuyo propósito funcionan sobre reglas tendentes a asegurar el control democrático y la participación económica de los asociados, lo que resulta consecuente con el principio de distribución socialista «...de cada cual según su capacidad, a cada cual según su trabajo» ${ }^{27}$ y con la «...supresión de la explotación del hombre por el hombre» 28 .

ran el día que vendrá un alguacil con la guardia rural a decirles que tienen que irse (...). A ese pueblo, cuyos caminos de angustias están empedrados de engaños y falsas promesas, no le íbamos a decir: "Te vamos a dar", sino: " ¡Aquí tienes, lucha ahora con todas tus fuerzas para que sean tuyas la libertad y la felicidad!".

En el sumario de esta causa han de constar las cinco leyes revolucionarias que serían proclamadas inmediatamente después de tomar el cuartel Moncada (...).

La segunda ley concedía la propiedad inembargable e intransferible de la tierra a todos los colonos, subcolonos, arrendatarios, aparceros y precaristas que ocupasen parcelas de cinco o menos caballerías de tierra, indemnizando el Estado o a sus anteriores propietarios a base de la renta que devengarían por dichas parcelas en un promedio de diez años.» Castro Ruz, F.: La Historia me absolverá, edición anotada por Álvarez Tabío, P. y Alonso Fiel, G., Ed. Oficina de Publicaciones del Consejo de Estado y Ed. Pueblo y Educación, La Habana, 2005, pp. 45-47.

25 Acta contentiva de la discusión del Proyecto de Ley de Reforma Constitucional, Décimo Período Ordinario de Sesiones, Tercera Legislatura de la Asamblea Nacional del Poder Popular, días 10, 11 y 12 de julio de 1992, p. 54.

26 Vega Vega, J.: Derecho Constitucional revolucionario en Cuba, Ed. Ciencias Sociales, La Habana, 1988, p. 159.

27 Artículo 14 de la Constitución socialista cubana de 1976 (actualizada).

28 ldem. 
Por estas y otras razones, los clásicos del marxismo, si bien abogaron por posturas radicales en la búsqueda de soluciones a los problemas de clase del proletariado y no concibiendo a las cooperativas como la vía esencial para la transición del capitalismo al socialismo, tampoco negaron nunca el importante papel que ellas podían jugar durante esta etapa29; por el contrario, reconocieron que una vez conquistado el poder político por los sectores populares, el rol de las cooperativas es consustancial a la construcción del socialismo ${ }^{30}$.

El confinamiento al que se ha sometido hasta hoy a las cooperativas en Cuba no debe ser erróneamente identificado como una cualidad del sistema de economía socialista, ni como una limitación impuesta por sus principios teóricos fundamentales.

Congruente con esta línea de pensamiento, los Lineamientos parten en su propuesta de eliminar los adjetivos que denotan limitación en cuanto a la naturaleza de las actividades a desarrollar por las cooperativas, al establecer en su numeral 25 que «se crearán las cooperativas de primer grado como una forma socialista de propiedad colectiva, en diferentes sectores...» lo que crea una expectativa favorable en cuanto a la diversificación de sus campos de acción para el futuro próximo. De hecho, en estudios recientes se plantean diversas propuestas para su desarrollo ${ }^{31}$ que llegan a proponer incluso que «...una vez que ello sea posible legalmente, debería considerarse promover la cooperativización de unidades empresariales estatales cuyas actividades no sean estratégicas... $»^{32}$.

29 «.... si la producción cooperativa (...) ha de sustituir el sistema capitalista; si las sociedades cooperativas unidas han de regular la producción nacional con arreglo a un plan común, tomándolo bajo su control y poniendo fin a la constante anarquía y a las convulsiones periódicas, consecuencias inevitables de la producción capitalista, ¿qué será eso entonces, caballeros, más que comunismo, comunismo realizable...?» Marx, C.: «La guerra civil en Francia», en http://www.marxists.org/espanol/m-e/1870s/gcfran/ guer.htm, consultado en septiembre de 2010.

30 Lenin destacó la «importancia gigantesca e inconmensurable» que adquiría la organización cooperativa, a saber: "Con la NEP hicimos una concesión al comercio privado; precisamente de ello emana (...) la gigantesca importancia de la cooperación. En el fondo, todo lo que necesitamos es organizar en cooperativas a la población en un grado suficientemente amplio y profundo... pues ahora hemos encontrado el grado de conjugación de los intereses privados, de los intereses comerciales privados, los métodos de su comprobación y control por el Estado, el grado de su subordinación a los intereses generales, lo que antes constituyó el escollo para muchos socialistas.» Lenin, V.I.: «Sobre la cooperación», en Obras escogidas en tres tomos, t. 3, Ed. Progreso, Moscú, 1961, p. 778.

31 Vid. Piñeiro Harnecker, C. (compiladora): Cooperativas y socialismo: Una mirada desde Cuba, Centro Martin Luther King, La Habana, 2011.

32 Ibidem, pp. 18-19. 


\subsection{Fines a cuyos efectos se concibe legalmente}

Los fines para los que se concibe la cooperativa - agropecuariaestán expresados en sentido restrictivo por la Constitución de la República: «...producción agropecuaria...» y «...obtención de créditos y servicios estatales...» ${ }^{33}$. Los propósitos de las cooperativas pueden ser mucho más heterogéneos e igual de consecuentes con la esencia socialista de la Constitución, por lo que su regulación taxativa en ella no es aconsejable.

No obstante estos fines previstos constitucionalmente, estudiosos del cooperativismo cubano como JIMÉNEZ GUETHÓN sostienen que, la creación de las cooperativas se inserta en las mega-finalidades propias del desarrollo rural emprendido con el triunfo de la Revolución y que consideró los siguientes aspectos:

- El fomento de asentamientos poblacionales para garantizar el bienestar de las comunidades.

- El desarrollo de una determinada infraestructura para el desarrollo del campo (comunidades, viales, transporte, electricidad, etc.).

— El desarrollo de programas de educación, salud, y otros servicios a la población.

- La creación de mejores condiciones laborales y de vida que propiciaron la elevación de las aspiraciones y motivaciones personales de los trabajadores del campo. ${ }^{34}$

Estas finalidades sociales vinculadas al desarrollo de las comunidades y de la calidad de vida de los cooperativista también fueron apreciadas como parte de la ratio para la existencia de las cooperativas agropecuarias por VEGA VEGA que las explica como contribución «...al desarrollo científico-técnico de la agricultura, así como al aprovechamiento óptimo de la tierra, a la vez que facilitaran mejores condiciones de vida para las familias campesinas» ${ }^{35}$.

33 Esta es causa fundamental para que en Cuba, pese a ser un Estado socialista, no exista una Ley de Cooperativas, sino una «Ley de Cooperativas de Producción Agropecuaria y de Créditos y Servicios».

34 Jiménez R.: «Las cooperativas agrícolas cubanas: una estrategia para el desarrollo del país», en Panorama da Realidade cubana-3 Cadernos do Ceam, año V, n. ${ }^{\circ} 19$ (agosto de 2005). Universidad de Brasilia. Centro de Estudos avancados Multidisplinares. Núcleo de estudios cubanos, citado por Jiménez Guethón, R.: Aspectos fundamentales del desarrollo cooperativo cubano, consultado en www.flacso.uh.cu/sitio_revista/ num3/articulos/art_RJimenez2.pdf, en junio de 2011

35 Vega Vega, J.: op. cit., p. 158. 
A pesar de que estas perspectivas programáticas de la concepción revolucionaria sobre el rediseño de las formas de vida y producción en el campo se expresaron efectivamente como fines de la política de desarrollo, no alcanzaron reflejo normativo que pusiera en evidencia la responsabilidad y el papel social de las cooperativas más allá del ámbito administrativo-productivo. Esto se hace evidente con la lectura de los artículos $8^{36}$ y $9^{37}$ de la LCPACS, que al consignar los fines fundamentales de las cooperativas agropecuarias cubanas, lo hace en extremo apegada al carácter reduccionista — por economicista - que hemos venido criticando.

En este sentido los Lineamientos resultan redundantes al plantear que las cooperativas tendrán «...la finalidad de producir y prestar servicios útiles a la sociedad... ${ }^{38}$, sin que se ponderen los potenciales valores democráticos y socializadores de la figura, hacia donde debe enrumbar en un futuro inmediato el ordenamiento jurídico cubano.

La razón para que estos esquemas del pasado se reiteren en planes correctores del modelo socioeconómico cubano, habría que bus-

36 «Artículo 8: Las cooperativas de Producción Agropecuaria tienen los fines fundamentales siguientes:

a) desarrollar con eficiencia económica la producción agropecuaria sostenible en atención a los intereses de la economía nacional, de la comunidad y de la propia cooperativa

b) utilizar racionalmente los suelos agrícolas, propiedad o en usufructo de la cooperativa y los demás bienes agropecuarios y recursos productivos con que cuenta

c) incrementar sostenidamente la cantidad y calidad de las producciones directivas y propiciar su rápida comercialización

d) desarrollar otras producciones agropecuarias y forestales y prestar servicios agropecuarios que hayan sido autorizados en su objeto social»

37 «Artículo 9: Las cooperativas de Créditos y Servicio tienen los fines fundamentales siguientes:

a) planificar, contratar, comprar, vender y utilizar en forma organizada y racional los recursos y servicios necesarios para sus miembros y la cooperativa, en razón de la producción agropecuaria

b) Gestionar, tramitar y colaborar en el control, la utilización y recuperación de los créditos bancarios necesarios para sus miembros y la propia cooperativa, destinados a la producción agropecuaria

c) Planificar y comercializar las producciones directivas de los miembros y de la cooperativa

d) Comercializar otras producciones y servicios autorizados en su objeto social

e) Adquirir, arrendar y explotar en forma colectiva los equipos agrícolas y de transporte y construir las instalaciones necesarias para mejorar la eficiencia en la producción y comercialización agropecuaria autorizadas en su objeto social».

38 Numeral 25 de los Lineamientos. 
carla - a nuestra consideración - en la dañina tradición de explicar a la cooperativa estrictamente como una forma de propiedad, lo que nos devuelve a la cuestión medular de su naturaleza jurídica abordada supra. Solo con una concepción transdisciplinaria que le permita al Derecho jugar su debido papel, se conseguirá superar estas limitaciones.

Para comprender la magnitud y adaptabilidad de los fines de las cooperativa puede partirse de un presupuesto esencial, aunque no único, que de alguna forma condiciona su desarrollo: «...lo que mueve a las cooperativas es la satisfacción de las necesidades de desarrollo humano de sus miembros; las cuales están inevitablemente ligadas a las necesidades de sus comunidades aledañas y de la nación, e incluso de la "gran familia humana" »39. Nada ajeno a esta quintaesencia es admisible como finalidad, y el alcance general de la misma habrá de buscarse en los conocidos Principios Cooperativos.

\subsection{Funcionamiento}

El funcionamiento de las cooperativas puede entenderse en dos planos bien definidos y separados aunque vinculados entre sí, el interno que explica la lógica de constitución, el régimen de los socios, los órganos sociales, régimen económico, la solución de conflictos; y el externo que abarca lo tocante a su relación como persona jurídica con otras personas naturales o jurídicas distintas de sus socios.

En la Constitución socialista cubana no se sientan principios generales para el control de la cooperativa por sus asociados, pues si bien se establece que ellas «....administran, poseen, usan, y disponen de los bienes de su propiedad...»40, la participación de los miembros en la empresa económica común que la cooperativa supone, siempre será más dinámica y compleja que el mero ejercicio de facultades sobre bienes; surgirán problemáticas de necesaria decisión colectiva, relaciones jerárquicas, de representación y otras interioridades que el ordenamiento jurídico debe encauzar hacia un destino apropiado.

De igual forma no existe claridad en cuanto a la naturaleza de la aportación de los asociados a la cooperativa, ni de la relación de esta aportación con su participación económica llegado el momento de percibir los beneficios.

39 Piñeiro Harnecker, C. (compiladora): op. cit., p. 3.

40 Artículo 20 de la Constitución socialista cubana de 1976 (actualizada), tercer párrafo. 
También se requiere precisión sobre el grado de autonomía e independencia de las cooperativas para planificar y orientar sus estrategias de desarrollo, con respecto, sobre todo, a los órganos de poder del Estado (a todos los niveles territoriales).

Sobre las líneas de proyecciones de las cooperativas para con la sociedad en general es pertinente que la Constitución siente pautas. La cooperativa - más si se concibe como una forma de producción socialista- tendrá siempre que estar ocupada en garantizar el desarrollo sustentable de la comunidad, y para ello deberá contar con las condiciones necesarias.

La importancia de la educación y la capacitación para la viabilidad de las cooperativas, ya sea al interior o al exterior de estas, ameritan que la Constitución se pronuncie en este sentido, obligando a su promoción tanto a las propias cooperativas, como al aparato institucional del Estado y a la comunidad en general.

La legislación especial que desarrolla el tema cooperativo hace una regulación bastante diferenciadora de los aspecto aludidos según se trate de las Cooperativas de Crédito y Servicios, las Cooperativas de Producción Agropecuaria y las Unidades Básicas de Producción Cooperativa, las tres formas de cooperativas admitidas en el ordenamiento jurídico cubano ${ }^{41}$.

Dentro de las principales cuestiones que manifiestan limitaciones se encuentran:

- En cuanto a su constitución como personas jurídicas, su supeditación a un sistema de creación por autorización modalidad limitada. 42

- La carencia de un régimen jurídico común para aspectos tan importantes como la determinación de la condición de socio, concepción de los órganos sociales y su periodo de mandato, el régimen de control democrático de los cooperativistas respecto a la gestión de estos, etc.

- Insuficiente nivel de protagonismo de las cooperativas y los socios en el enfrentamiento de las contingencias existenciales de

41 Respecto a las características particulares del funcionamiento de cada una de los elementos que integran las relaciones internas y externas de los diferentes tipos cooperativos aludidos Cfr. Fernández Peiso, L.A.: El fenómeno cooperativo y el modelo jurídico nacional. Propuesta para la nueva base jurídica del cooperativismo en Cuba, tesis presentada en opción al grado científico de Doctor en Ciencias Jurídicas, Cienfuegos, 2005.

42 Con este sistema de constitución, las cooperativas están sujetas a la voluntad administrativa, que posee la facultad de crearlas a través de un acto administrativo de autorización. 
las mismas, debido a un paternalismo excesivo de la Administración Pública.

- Ineficiente empleo del contrato en las relaciones empresariales de las cooperativas, como vía adecuada para la exigencia y cumplimiento de responsabilidades jurídicas ${ }^{43}$.

- Las reservas aun no muy explotadas de la cooperativa en sus relaciones con las organizaciones políticas, sociales y de masas; relaciones estas que deben diversificarse desde la comprensión del rol social y activo de las cooperativas en el entorno comunitario, como sujetos del desarrollo local.

En muchos de estos aspectos se hace relevante la cuestión de la autonomía de las cooperativas ${ }^{44}$ como principio rector de su funcionamiento ${ }^{45}$ que debe ser revisado para su perfeccionamiento en la legislación cubana, algo que ya parece estar siendo valorado pues «...los Lineamientos parecen indicar que se les otorgará las facultades de autogestión que las caracterizan universalmente y sin las cuales no es posible su gestión democrática. Esperamos que la Ley de cooperativas resuelva las insuficiencias del marco legal vigente para las cooperativas agropecuarias» ${ }^{46}$.

43 El X Congreso de la ANAP «...adoptó un grupo de acuerdos, entre ellos figuró la recomendación de revisar la legislación establecida para la contratación agropecuaria, y pidió enfatizar en la necesidad de exigir a las direcciones de las cooperativas y de las empresas su adecuada implementación». Molina, Y. y Cardoso, D.: Producción de alimentos: Aristas de la contratación, publicado en http://www.campesinocubano.anap. cu/2011/junio/produccion.htm, y consultado en junio de 2011.

44 "Cuarto: "Autonomia e independencia". Las cooperativas son organizaciones autónomas de auto ayuda administradas por sus asociados. Si intervienen en acuerdos con otras organizaciones, incluidos los gobiernos, o captan capital de fuentes externas, lo hacen en términos que aseguren el control por parte de los asociados y mantengan su autonomía cooperativa.» Los principios cooperativos para el siglo XXI (Documento de referencia acerca de la Declaración sobre la Identidad Cooperativa), publicado por El Hogar Obrero: Cooperativa de Consumo, Edificación y Crédito Ltda., en http://www. elhogarobrero1905.org.ar, consultado en diciembre de 2009.

45 En todas partes del mundo las cooperativas se ven afectadas por sus relaciones con el Estado: los gobiernos determinan el marco legislativo dentro del cual deben funcionar y con sus políticas fiscales, económicas y sociales, ayudan o perjudican a las cooperativas; realidad ante la que el principio destaca la importancia de que las cooperativas mantengan su autonomía -y con ella su identidad-. Pero, sin embargo, esta autonomía no debe significar que las cooperativas actúen de espaldas o en contra de los programas nacionales de desarrollo, contentivos de las necesidades socioeconómicas del espacio en que se desenvuelven, sino que - por el contrario- deben participar en la elaboración de los mismos y trabajar por su realización.

46 Piñeiro Harnecker, C. (compiladora): ob. cit., p. 3. 


\section{A modo de conclusión}

Sobre la base de las anteriores valoraciones, es oportuno concluir y recomendar que el ordenamiento jurídico cubano en materia de cooperativas, a la luz del actual proceso de restructuración y perfeccionamiento del modelo socioeconómico del país:

- Debe redefinir la cuestión relativa a la naturaleza jurídica de la cooperativa a partir de una visión transdisciplinaria que supere los estrechos límites a los que ha estado constreñida hasta ahora como forma de propiedad y pase a contemplarse como una figura asociativa autónoma con contenido y esencia propia.

- Debe ampliar el reconocimiento del derecho a asociarse en cooperativas, sin limitación por el sector de la economía en que se desenvuelven los sujetos para los que se contemple.

- Deberá contemplar a las cooperativas con una formulación general que les permita operar más allá de los límites de la esfera agropecuaria (espacio al que han estado confinadas hasta ahora), alcanzando todos los sectores de la economía en que las necesidades socioeconómicas y culturales de la sociedad las demanden.

- Conveniente sería que los fines fundamentales que se contemplen para la cooperativa superen su actual contenido economicista, reivindicando y canalizando sus amplias potencialidades democratizadoras y socializadoras.

- Ajustado sería que, sobre la base de un análisis crítico de los Principios Cooperativos, se reestructure el funcionamiento interno y externo de la cooperativa en Cuba, a fin de garantizar un desenvolvimiento más autónomo y democrático de la empresa, y una mayor contribución de ésta a la comunidad en que se desenvuelve. 